\title{
Comparative Analysis of the Serratus Anterior Muscle Activity When Right and Left Knee Lift during Quadruped Position on Push Up Plus
}

\author{
Ki Seok Nam¹, Ji Woong Kim¹, Ji Won Park² \\ 'Department of Physical Therapy, Yeungnam University College, Daegu; ${ }^{2}$ Department of Physical Therapy, College of Bio and Medical Science, Daegu \\ Catholic University, Gyeongsan, Korea
}

Purpose: This study examined the effects of the right or left knee lift during push up plus in the quadruped position on the serratus anterior (SA) muscle activity.

Methods: Twenty-one subjects (male 11, female 10) performed the quadruped position on push up plus. The muscle activities of the lower trapezius (LT), SA, and upper trapezius (UT) were measured by surface electromyography. Repeated measurements of one-way ANOVA were performed for statistical analysis of the data, and the criterion for statistical significance was set to $p<0.05$ and comparative analysis of the UT and SA ratio using a Paired t-test.

Results: The right SA increased the muscle activity of the right knee lift during quadruped position push up plus $(p<0.05)$. In particular, the right SA muscle activity was higher than the left. In addition, comparative analysis of the UT and SA ratio to the right knee lift during quadruped position push up plus was performed $(p<0.05)$. The right was found to be a significant statistic compared to the left, but the left SA increased the muscle activity of the left knee lift during quadruped position push up plus $(p<0.05)$. The left SA muscle activity was higher than right. In addition, comparative analysis of UT and SA ratio to the left knee lift during quadruped position push up plus was performed $(p<0.05)$. The left was found to be a significance statistic than the right. In addition, the interaction effect between the groups showed significant differences $(p<0.05)$.

Conclusion: Knee lift during push up plus is recommended for the selective activation of a research exercise protocol of one side of the serratus anterior.

Keywords: Quadruped position, Knee lift, Serratus anterior

\section{서 론}

날개뼈의 불안정한 동적 안정성은 목과 어깨관절 주변의 신경계와 근골격계의 기능 부전을 발생시킨다. 어깨관절 복합체는 해부학적 관절인 오목위팔관절, 봉우리빗장관절, 복장빗장관절과 생리학적 관 절인 어깨가슴 관절이 포함되고 어깨관절 복합체에서 운동의 중심 으로 다축성 관절로 어깨의 지지력 안정성을 유지하기 위하여 빼나 인대보다 안정화근육의 앞톱니근, 위등세모근과 아래등세모근이 포 함된다. ${ }^{2-4}$ 또한 앞톱니근과 위등세모근은 어깨가슴관절의 주요한 안 정근육으로써 아래등세모근과 함께 어깨뼈를 가슴에 적절히 위치시 키며 동적인 안정성을 제공한다. ${ }^{5}$ 특히 앞톱니근은 날개뼈의 운동과
조절에 있어서 매우 중요하게 작용하는데 다른 어떤 어깨가슴관절 의 근육들보다 날개뼈의 위쪽돌림(upward rotation)과 뒤기울림(posterior tilt)를 만드는 지레팔의 길이가 길기 때문에 어깨뼈 운동의 주 동근이 되며 어깨뼈의 날개어깨뼈(winging scapula) 방지에 중요한 역 할을 하지만 67 근육들의 비정상적 활동패턴으로 인하여 어깨빼 근육 의 불균형이 나타나게 된다.8

어깨뼈의 위쪽돌림동안 가장 먼저 작용하는 안정화 근육은 아래 등세모근과 앞톱니근이며 위쪽돌림시 초기 단계에 위등세모근과 앞 톱니근은 짝힘으로 작용하여 어깨관절의 위쪽돌림이 일어난다.49,10 특히 앞톱니근은 어깨가슴관절의 안정성과 운동에 매우 중요하게 작용하며 다른 어깨가슴관절의 안정화 근육들 보다 어깨뼈의 위쪽 
돌림과 뒤기울임을 만드는 지렛팔이 길기 때문에 어깨가슴관절 운 동의 주동근으로 작용하고 날개어깨뼈를 방지하는 역할을 한다. ${ }^{6,12}$ 앞톱니근은 효과적인 어깨관절의 외전근이며 어깨뼈의 상방회전과 견갑골의 흥곽에 부착시키는데 중요한 역할을 한다." 안정화 근육들 의 불균형이 존재하는 환자들에게 안정화 근육들의 전반적인 근활 성도를 높이는 운동보다는 안정화 근육의 힘의 불균형은 최소로 유 지하며 선택적으로 활성화 할 수 있는 운동이 필요하다.

전통적인 상지 재활프로그램은 근력강화를 위해 열린사슬운동이 사용되어왔다. 최근에는 저자들이 상지 재활을 위해 닫힌사슬운동 을 이용하고 있고 ${ }^{13}$ 닫힌사슬운동은 사지의 원위부는 고정되고 근위 부와 원위부에 저항을 동시에 적용시 일어나는 운동으로 ${ }^{14}$ 동적인 근 육의 안정성을 위하여 동시 수축으로 원심성수축, 관절압박력으로 전단력을 낮추어 관절의 안정성을 높인다. 기계적 수용기는 관절낭 의 압력 변화에 반응하여 고유수용성감각을 활성도를 높인다. ${ }^{15}$

닫힌사슬운동의 네발기기 자세에서의 푸시업플러스 운동은 주관 절이 폄하였을 때 최대한 어깨뼈를 내밈 하여 일반적인 푸시업 운동 을 수정하여 등세모근 아래섬유 활성과 높은 앞톱니근의 활성을 이 끌어내기 때문에 상지재활프로그램에서 앞톱니근의 선택적 활성화 를 높이는데 사용된다.2.,13 최근 푸시업플러스 동작 중에도 지지면의 불안정성을 높인 불안정한 상태에서의 운동방법이 가장 효율성이 높은 것으로 알려져 있고 ${ }^{16}$ 불안정한 지지면에서 팔굽혀펴기 운동을 할 때 위등세모근/앞톱니근 비는 유의하게 낮아졌으며 이는 불안정 한 지지면을 이용한 운동자극으로 앞톱니근의 근활성도가 증가 된 다고 하였다. 푸시업플러스 동작시 불안정성을 높이기 위해 지지면을 줄이는 방법으로 한 쪽다리 들기를 많이 적용하고 있다.

푸시업플러스 동작 시 오른쪽 어깨근의 활성도는 동측(오른쪽)의 반대측(왼쪽) 다리를 들 때 보다 동측(오른쪽)의 다리를 들었을 때 근 전도 활성도 값이 올라가는 것을 확인할 수 있었는데, 이는 네발기기 자세에서의 중력중심(center of gravity)이 동측 다리를 들 때 동측 기 저면(base of support)의 소실을 보상하기 위하여, 신체의 중력 중심이 동측(오른쪽) 다리를 든 쪽 어깨로 집중되어 어깨근 활성도가 높아 진 결과라고 볼수 있다.17

선행연구들에서 푸시업플러스로 앞톱니근을 강화하기 위해 어깨 근의 각도, 지지면의 불안정성 등과 같은 변수를 사용하여 양쪽 어깨 의 문제로 인한 환자, 한쪽 어깨근의 문제를 가지는 스포츠 선수, 일 반인 등을 대상으로 실험하여 모두 양쪽 앞톱니근의 활성도를 높이 는 운동을 제시한 반면 한쪽 어깨근의 선택적 활성도를 높이는 운동 은 없었다. ${ }^{13}$

따라서 본 연구에서는 네발기기자세에서 오른쪽과 왼쪽 무릎들 기 동작이 한쪽 앞톱니근의 선택적 활성도에 어떠한 영향을 미치는 지 연구하였다.

\section{연구 방법}

\section{1.연구대상}

본 연구의 대상자는 20 대 21 명(남성 11 명, 여자 10 명)의 건강한 정상 성 인을 대상으로 하였다. 연구대상의 제외 기준은 1) 어깨관절의 가동 성 제한이 있는 자, 2) 어깨관절의 확연한 불안정성이 있는 자, 3) 어깨 에 수술 경험이 있는 자, 4) 최근 3개월 내에 어깨나 목에 통증이 있는 자, 5) 유착성 관절낭염 또는 흥곽출구증후군 등의 목과 어깨질환 병 력이 있는 자로 설정하였다(Table 1).

모든 대상자들은 실험하기 전, 실험 과정에 대해 충분한 설명을 듣 고 실험 참여에 자발적으로 동의를 하였다. 임상시험심사위원회(Institutional Review Board, IRB)에 의뢰하여 승인(승인번호: CRI00006101)을 받은 후 연구진행을 하였다.

\section{2. 실험방법}

1) 측정도구

(1) 표면 근전도(Surface electromyography)

근육의 활성도 비교를 위해 8채널 무선 표면 근전도 WEMG-8 (Laxtha, USA)를 사용했다. 표면전극( $\mathrm{Ag} / \mathrm{AgCI} 222,3 \mathrm{M}$, Korea)은 6채널을 사용하여 오른쪽-왼쪽 앞톱니근, 위등세모근, 아래등세모근에 부착 하였으며 표면 전극 부착 부위의 피부 저항을 줄이기 위해 알코올 솜 으로 피부각질층을 제거하였다.

\section{(2) 스포츠 매트}

오른쪽 왼쪽 무릎을 들기에 용이하게 실험자가 스포츠매트를 이용 하여 실험에 맞게 제작하였다. 대상자들의 평균 키는 남자 $176.27 \mathrm{~cm}$, 여자 $159.5 \mathrm{~cm}$ 로 네발기기자세에서 어깨관절 $90^{\circ}$, 무릎관절 위치할 때 손목의 붓돌기(styloid process)에서 무릎이 지면이 닿는 위치까지 평균 남자는 $78 \mathrm{~cm}$, 여자는 $64 \mathrm{~cm}$ 를 필요로 하여 양손의 가이드라인 을 세로 $10 \mathrm{~cm}$ 아래쪽에 위치하였고 오른쪽-왼쪽 무릎의 위치는 가 로 $20 \mathrm{~cm} \times$ 세로 $30 \mathrm{~cm}$ 로 하였다.

\section{2) 근전도 전극 부착}

실험실의 온도를 $25^{\circ} \mathrm{C}$ 로 일정하게 유지한 후, 근전도 수집을 위해 오 른쪽/왼쪽 각각 세 개의 근육에 대한 전극부착부위를 한 번 더 확인

Table 1. General characteristics of subjects

$(n=21)$

\begin{tabular}{lcc}
\hline Variables & Mean \pm SD & Range \\
\hline Age $(\mathrm{yr})$ & $21.95 \pm 1.98^{\mathrm{a}}$ & $20-26$ \\
Height $(\mathrm{cm})$ & $168.28 \pm 9.29$ & $152-182$ \\
Weight $(\mathrm{kg})$ & $62.52 \pm 13.18$ & $43-89$ \\
\hline
\end{tabular}

avalues are mean $\pm S D$. 
후 각 근육의 근섬유 방향을 따라 활성전극(activate electrode)과 기준 전극(reference electrode)을 수평으로 부착하였다. 각 전극 중심 사이 의 거리는 $2 \mathrm{~cm}$ 이내로 부착하였다. 각 근육별 구체적인 전극 부착 부 위로서 위등세모근은 7 번째 목뼈의 가시돌기와 어깨부리의 사이, 아 래등세모근은 어깨뼈의 아래각 높이에 해당하는 허리뼈의 가시돌기 에서 가쪽 $2 \mathrm{~cm}$ 부위 그리고 앞톱니근은 겨드랑부위의 5-6번째 갈비 뼈 높이에서 넓은등근의 앞쪽부위로 하였다. ${ }^{4}$

\section{3) 근전도 신호처리방법}

채널을 지정하여 각 채널에서 근전도 신호를 받을 수 있도록 하며 근 전도 신호의 표본추출률은 $1,000 \mathrm{~Hz}$ (1,000 samples/second)로 증폭된 파형을 60-500 Hz의 대역통과필터(band pass filter)로 필터링하였다. 잡음을 제거하기 위해 $60 \mathrm{~Hz}$ 의 노치필터(notch filter)를 이용하고 각 근육이 수축한 시간 동안 수집된 신호를 정량화 하기 위해 실효평균 값(root mean square, RMS) 처리를 하였다.

\section{3. 운동 프로그램}

실험을 시작하기 전 실험자들의 실험에 사용할 도구와 동작을 10 분 간 충분히 설명한 후에 푸시업플러스 동작을 10 분간 실시 후 다음 대 상자가 전 대상자의 실험을 관찰하도록 하였다. 대상자들의 교육은 네발기기 자세를 하고 감사자는 10 분간 연습한 운동을 패드를 이용 하여 실험 중 대상자의 어깨올림, 무릎들기, 체중이동에 주의 후 실시 를 하였다. 최대 수축 범위에서 5 초간 유지한 후 3 초 동안 휴식 후 3 회 반복하였다.

\section{1) 오른쪽 무릎들기 시 푸시업플러스 동작}

- 네발기기 자세에서 실험자가 제작한 스포츠매트에서 양손을 가 이드라인에 어깨넓이만큼 벌린다.

- 어깨관절 $90^{\circ}$, 무릎관절 $90^{\circ}$ 굽힘 후 실험자의 지도아래 다음단계 로 넘어간다.

- 실험용 스포츠매트에서 오른쪽 무릎 들기 시 왼쪽 무릎의 높이 와 동일한 위치에서 오른쪽 어깨의 체중이동을 대상자에게 확인 한다.

- 대상자는 푸시업플러스 동작을 실시한다(PUP with right knee lifting).

\section{2) 왼쪽 무릎들기 시 푸시업플러스 동작}

- 네발기기 자세에서 실험자가 제작한 스포츠매트에서 양손을 가 이드라인에 어깨넓이만큼 벌린다.

- 어깨관절 $90^{\circ}$, 무릎관절 $90^{\circ}$ 굽힘 후 실험자의 지도아래 다음단계 로 넘어간다.
- 실험용 스포츠매트에서 왼쪽 무릎 들기 시 오른쪽 무릎의 높이와 동일한 위치에서 왼쪽 어깨의 체중이동을 대상자에게 확인한다. - 대상자는 푸시업플러스 동작을 실시한다(PUP with left knee lifting).

\section{4. 자료분석}

위등세모근, 아래등세모근, 앞톱니근의 근활성도를 위해 각 측정 근 육의 길이가 최대 신장 상태에 비해 중간 정도의 길이를 가지는 상태 인 정상 관절가동범위의 중간 범위에 서 최대 등척성 수축(Maximal Voluntary Isometric Contraction, MVIC) 시 근활성도를 측정하였다. 5 초 동안의 자료 값의 수집된 신호를 정량화 하기 위해 실효평균값 (Root Mean Square, RMS) 처리를 하였다.

측정은 5 초간 3 회 반복 측정하며 각 근육의 측정 시 1 분간 휴식을 주었다. 최대 등척성 수축 과정은 위등세모근 측정은 등받이 의자에 등받이 등을 기댄 후 검사자가 측정하는 측의 어깨를 고정하고 실험 자가 측정하는 어깨를 들어 올리는 동작을 취하도록 하였으며, 아래 등세모근의 측정은 실험 대상자가 엎드려 누운 자세에서 측정하는 측의 팔꿈치를 펴고 팔을 바닥과 수평한 상태에서 $90^{\circ}$ 수평외전한 상 태에서 검사자는 팔을 고정하고, 팔을 펴는 동작을 취하도록 실시하 였다. 앞톱니근은 실험 대상자가 바로 누운 상태에서 어깨를 $90^{\circ}$ 굴곡 한 후 팔꿈치를 편 후 검사자는 상완을 고정하고 어깨의 올림 동작을 방지하기 위해 실험 전 설명 후 올림동작이 나오지 않도록 지도와 함 께 실험자는 팔을 앞으로 내밈 동작을 실시하였다.

\section{5. 통계방법}

자료의 통계처리는 통계프로그램 윈도우용 SPSS version 18.0 (SPSS Inc., Chicago)을 사용하였고 오른쪽-왼쪽 무릎들기 시 오른쪽-왼쪽 위등세 모근, 아래등세모근, 앞톱니근 한쪽 3 개의 근육 양쪽 6 개의 근육군 상 관관계 활성도 비교를 위하여 Repeated Measure ANOVA방법을 사용 하였고 사후검정 방법은 Bonferroni 방법을 사용하였다. 또한 오른쪽왼쪽 개별적 근육군의 비교는 independent t-test 방법을 사용하였다. 동 일한 방법으로 오른쪽-왼쪽 위등세모근/앞톱니근의 근활성도 비를 비 교 분석하였다. 연구의 통계적 유의 수준은 $\alpha=0.05$ 하였다.

\section{결 과}

\section{1. 네발기기자세에서 푸시업플러스 동작 시 오른쪽 무릎들기}

\section{1) 오른쪽 무릎들기 시 근육별 활성도 비교}

각 근육군의 근활성도의 구성비 중 앞톱니근을 제외한 위등세모근, 아래등세모근에서는 유의한 상호작용이 나타나지 않았다. 오른쪽 무릎들기 시 근육군의 위등세모근에서는 오른쪽이 $15.29 \pm 2.60$, 왼 쪽이 $15.94 \pm 2.65$ 이 왼쪽보다 0.65 증가되었고, 오른쪽 무릎들기 시 오 
Table 2. Comparative analysis of UT and SA ratio in the knee lifting

\begin{tabular}{lcccc}
\hline & UT/SA (Right) & UT/SA (Left) & $t$ & $p$ \\
\hline Right knee lifting & $0.236 \pm 0.212$ & $0.404 \pm 0.352$ & -2.545 & $0.019^{*}$ \\
Left knee lifting & $0.394 \pm 0.268$ & $0.256 \pm 0.194$ & 2.132 & $0.046^{*}$ \\
\hline
\end{tabular}

Values are mean $\pm S D$

UT: Upper trapezius, SA: Serratus anterior.

${ }^{*} p<0.05$.

른쪽-왼쪽 위등세모근의 통계적으로 유의한 차이는 없었다( $\mathrm{p}>0.05)$. 아래등세모근에서는 오른쪽 $25.06 \pm 4.95$, 왼쪽 $36.74 \pm 3.35$ 으로 오른쪽 이 왼쪽 보다 -11.68 감소되었고 통계적으로 유의한 차이는 없었다 ( $p>0.05)$. 앞톱니근에서는 오른쪽 $63.86 \pm 2.59$, 왼쪽 $45.39 \pm 3.51$ 에서는 오른쪽이 왼쪽 보다 18.47 증가되었고 통계적 유의성이 있었다 $(\mathrm{p}<0.05)$.

2) 오른쪽 무릎 들기에서 위등세모근과 앞톱니근 근활성도 비 비교 오른쪽 무릎 들기에서 위등세모근/앞톱니근의 근활성도는 오른쪽 $0.24 \pm 0.21$, 왼쪽 $0.40 \pm 0.35$ 으로 오른쪽-왼쪽 위등세모근/앞톱니근 비 (UT/SA Ratio)에서 통계적으로 유의한 차이가 있었다 $(\mathrm{p}<0.05)$ (Table 2).

\section{2. 네발기기자세에서 푸시업플러스 동작 시 왼쪽 무릎들기}

1) 왼쪽 무릎들기 시 근육별 활성도 비교

각 근육군의 근활성도의 구성비 중 앞톱니근을 제외한 위등세모근, 아래등세모근에서는 유의한 상호작용이 나타나지 않았다. 왼쪽 무 릎들기 시 근육군의 위등세모근에서는 오른쪽 $13.67 \pm 9.83$, 왼쪽 $16.51 \pm 12.45$ 으로 왼쪽이 오른쪽 보다 2.84 증가되었고, 통계적으로 유 의한 차이는 없었다 $(\mathrm{p}>0.05)$. 아래등세모근에서는 오른쪽 $28.18 \pm$ 16.95 , 왼쪽 $23.59 \pm 13.65$ 으로 왼쪽이 오른쪽 보다 4.59 감소되었고 통 계적으로 유의한 차이는 없었다( $\mathrm{p}>0.05)$. 앞톱니근에서는 오른쪽 $35.25 \pm 8.47$, 왼쪽 $65.48 \pm 14.67$ 에서는 왼쪽이 오른쪽 보다 30.23 증가되 었고 통계적 유의성이 있었다 $(\mathrm{p}<0.05)$.

\section{2) 왼쪽 무릎 들기에서 위등세모근과 앞톱니근 근활성도 비 비교} 왼쪽 무릎들기에서 위등세모근/앞톱니근의 근활성도는 오른쪽 0.39 \pm 0.27 , 왼쪽 $0.26 \pm 0.19$ 으로 오른쪽-왼쪽 위등세모근/앞톱니근 비(UT/ $\mathrm{SA}$ Ratio)에서 통계적으로 유의한 차이가 있었다 $(\mathrm{p}<0.05)($ Table 2$)$.

\section{고 찰}

본 연구에서는 20 대 21 명(남성 11 명, 여자 10 명)의 건강한 정상 성인을 대상으로 네발기기자세에서 오른쪽과 왼쪽 무릎들기 동작으로 한 쪽의 앞톱니근의 활성도에 어떠한 영향을 미치는지 근전도를 이용하 여 연구하였다. 네발기기자세에서 무릎들기시 근육별 활성도를 비교 한 결과 오른쪽 무릎들기와 왼쪽 무릎들기 모두에서 오른쪽과 왼쪽
의 위등세모근과 아래등세모근의 근전도 활성도는 통계적으로 유의 한 차이가 없었다. 반면 앞톱니근은 오른쪽 무릎들기 시 동측인 오른 쪽 앞톱니근에서 통계적으로 유의하게 높은 근전도 활성도를 나타내 었고, 왼쪽 무릎들기 시에도 동측인 왼쪽 앞톱니근에서 통계적으로 유의하게 높은 근전도 활성도를 나타내었다. 또한 무릎들기 시에 위 등세모근과 앞톱니근의 근활성도 비를 비교한 결과 무릎들기를 한 반대쪽 어깨의 위등세모근과 앞톱니근의 근활성도가 통계적으로 유 의하게 낮은 결과를 나타내었다.

근골격계 동작에 관한 연구하는 임상전문가들의 연구도구로 근전 도를 사용하여 기능과 장애를 연구하고 있으며, 근전도는 근활성도 의 양과 패턴 분석에서 비교적 용의하게 임상에서 사용되는데 살아 있는 인간의 아주 유용한 연구방법이다.919 이에 따른 안정근 연구에 서는 내측광근/외측광근 근활성도 비 비교에서 일반적으로 무릎관 절을 폄할 때 대퇴슬개통증 증후군 환자들에게서 내측광근/외측광 근 활성도 비 비교 시 열린사슬 운동을 할 때 보다 닫힌사슬 운동을 하는 동안 높게 나타났다고 하였다. 닫힌사슬 운동은 몸쪽 분절에 고 정되어 있는 상태에서 몸쪽 분절에서 먼쪽 분절 저항을 적용할 때 일 어나는 운동으로 ${ }^{14}$ 동적인 근육의 안정성 높이기 위한 동시수축으로 원심성 수축이 우세하며, 관절 압박력으로 전단력을 감소시켜 관절 의 안정성을 높이고, 기계적 수용기는 관절낭의 압력 변화에 민감하 게 반응하여 고유수용성 활성화를 높인다.

또한 닫힌사슬 운동은 근력 강화의 주요 프로그램으로 길항근이 서로 원심성으로 작용하여 손상된 관절의 안정성에 많은 역할을 한 다. ${ }^{15}$ 어깨가슴관절을 안정화시키기 위하여 많은 연구자들이 앞톱니 근에 관심을 두고 있고, 앞톱니근을 선택적인 강화를 위한 운동프로 토콜에 대해서 연구하고 있다. ${ }^{48}$ 위등세모근의 근활성도가 나타나거 나 앞톱니근, 위등세모근의 불균형이 있는 대상자들에게 다양한 형 태의 푸시업플러스 운동을 실시한 결과 일반적인 푸시업플러스에서 앞톱니근의 근활성도가 높게 측정되었고 푸시업플러스 운동은 낮은 위등세모근 근활성도를 보이는 운동이며, 앞톱니근 강화와 어깨안정 화 및 근육 불균형의 감소를 하기 위해 적절한 운동프로토콜의 하나 라고 하였다. 4.8

푸시업플러스 동작 시 어깨안정근의 손의 지지면의 다양한 넓이에 따른 영향에서 양손의 위치가 견봉의 수직하는 위치인 어깨넓이에 서 앞톱니근의 높은 증가를 확인하였고, ${ }^{20}$ 불안정한 지지면에서 팔굽 혀펴기 운동을 할 때 위등세모근/앞톱니근 비는 유의하게 낮아졌으 며 이는 불안정한 지지면을 이용한 자극으로 앞톱니근의 근활성도 가 증가된다고 하였다. 푸시업플러스 동작 시 불안정성을 높이기 위 해 지지면을 줄이는 방법으로 한 쪽다리 들기를 많이 적용하고 있다.

$\mathrm{Jo}^{17}$ 의 선행연구에서 푸시업플러스 동작 시 동측과 반대측 다리 들 기에 따른 우측 어깨근 활성도 비교 분석에서는 오른쪽 어깨근의 동 
측(오른쪽)과 반대측 엉덩관절과 무릎관절을 $90^{\circ}$ 폄한 후 양손을 슬 링을 이용하여 불안정성을 증가하여 네발기기자세에서 푸시업플러 스 동작을 실시하였고 동측(오른쪽)의 다리들기에서 앞톱니근의 활 성도가 반대측(왼쪽)보다 증가된 것을 확인할 수 있었다.

푸시업플러스를 이용하여 앞톱니근을 강화하는 방법으로 어깨근 의 각도, 지지면의 불안정성 등과 같은 변수를 이용하는 방법이 제안 되었으며, 양쪽 어깨의 문제로 인한 환자, 한쪽 어깨근의 문제를 가지 는 스포츠 선수, 일반인 등에서 실험이 이루어졌지만 모두 대상자의 앞톱니근의 양쪽 활성도를 높이는 운동만을 제안하였고, 한쪽 어깨 근의 선택적 활성도를 높이는 운동은 없었다..$^{8,19}$ 위등세모근과 앞톱 니근의 활성도에서는 동측(오른쪽) 다리들기 시에 반대측(왼쪽) 다리 들기 시 보다 활성도가 높아졌지만, 아래등세모근에서는 본 연구와 동일하게 감소한 결과를 보였다. 선행연구에서는 아래등세모근의 경 우에만 반대편 다리를 들 때 동측(오른쪽) 다리 들기에 비해 높은 근 활성도를 나타낸 것은 반대측 다리인 왼쪽다리 들기 시 왼쪽 골반의 안정성을 제공하기 위해 오른쪽 아래등세모근이 반대측 하부 몸통 근으로 역할을 한 것으로 예상하였다. ${ }^{10}$

선행논문에서 다리를 엉덩관절 $90^{\circ}$, 무릎관절 $90^{\circ}$ 와 지지지면의 불안정성을 높이기 위해 양손을 슬링을 이용하였지만 본 연구에서 는 불안정성을 줄이기 위해 다리들기를 무릎들기로 양손을 안정적 인 지지면을 이용하였지만 아래등세모근의 활성도 감소는 동일하였 다. 선행 연구에서는 연구의 결과 중 대부분 어깨근 활성도가 반대측 (왼쪽) 다리 들기에 비해 동측(오른쪽) 다리 들기 시 높아진 이유는 신 체의 중력중심(center of gravity)이 동측(오른쪽) 다리를 들 때 동측의 기저면(base of support)이 소실되는 것 을 보상하기 위한 것이 한 가지 원인으로 추측되어지고 또한 동측 다리를 들 때 신체의 중력 중심이 보다 소실된 기저면 측으로 가중되기 때문에 동측(오른쪽) 앞톱니근 의 활성도가 높아진 것으로 추측하였다.

본 연구에서도 무릎들기 시 기저면의 소실되는 어깨근의 불안정성 과 기저면의 소실로 인한 중력중심의 이동으로 인하여 체중의 가중 을 대상자들에게서 구두를 통해 확인할 수 있었고 기저면의 소실을 골반의 이동으로 보상하려는 움직임을 완벽하게 통제하지 못하였다. 그러나 21 명의 남 11 명, 여 10 명의 일반인을 대상으로 하여 실험하였 지만 성별에 상관없이 실험자들의 연구자의 운동프로그램을 사용하 여 푸시업플러스 동작을 할 때 기존의 양쪽 앞톱니근의 운동프로토 콜과는 다르게 한쪽 어깨의 선택적 활성화를 위한 좋은 운동프로토 콜이 될 것이다.

본 연구에서는 네발기기자세에서 오른쪽 무릎들기와 왼쪽무릎들 기를 할 때 앞톱니근 근활성도 비교에서 연구결과에서는 오른쪽 무 릎들기 시 오른쪽 어깨근의 위등세모근, 아래등세모근, 앞톱니근 근 활성도가 왼쪽과 비교 시 통계적으로 유의하였고 왼쪽 무릎들기 시
왼쪽 어깨근과 오른쪽 어깨근 비교 시에 동일하게 통계적으로 유의 하였다. 오른쪽 무릎들기 시에 오른쪽과 왼쪽의 각 근육군의 통계에 서는 위등세모근과 아래등세모근은 통계적으로 유의하지 않았다. 하 지만 앞톱니근은 통계적으로 유의하였다. 왼쪽 무릎들기 시에도 통 계적으로 동일한 결과를 확인할 수 있었다. 위등세모근과 앞톱니근 의 활성도비 비교 분석 시 무릎들기를 이용하여 한쪽 어깨근의 활성 도를 높이면서 낮은 위등세모근의 활성도를 확인할 수 있었으며 오 른쪽과 왼쪽을 비교할 때 통계적으로 유의하였다.

본 연구에서 오른쪽 무릎들기 시 오른쪽 앞톱니근의 활성도 증가 를 확인할 수 있었고, 왼쪽 무릎들기 시 왼쪽 앞톱니근의 활성도 증가 를 동일하게 확인할 수 있었다. 이는 양측 앞톱니근의 활성도를 높이 는 운동 프로토콜을 변형하여 한쪽 앞톱니근의 선택적 활성도를 증 가시킬 수 있는 운동프로토콜로 사용할 수 있음을 제안한다.

\section{REFERENCES}

1. Kim DH, Kwon OY, Yi CH et al. The Effects of 4-week serratus anterior strengthening exercise program on the scapular position and pain of the neck and interscapular region. Phys Ther Korea. 2007;14(4):58-65.

2. Decker MJ. Hintermeister RA, Faber KJ et al. Serratus anterior muscle activity during selected rehabilitation exercise. Am J Sports Med. 1999;27(6):784-91.

3. Hess SA. Functional stability of the glenohumeral joint. Man Ther. 2000;5(2):63-71.

4. Lear LJ, Gross MT. An electromyographical analysis of the scapular stabilizing synergists during a push up progresstion. J Orthop Sports Phys Ther. 1998;28(3):146-57.

5. Mottram SL. Dynamic stability of the scapula. Man Ther. 1997;2(3):12331.

6. Inman VT, Saunders JB, Abbott LC. Observations of the function of the shoulder joint. Clin Orthop Relat Res. 1996;330(9):3-12.

7. Ellenbecker TS. Clinical examination of the shoulder. St. Louis, Elsevier Saunders. 2004.

8. Ludewig PM, Hoff MS, Osowski EE et al. Relative balance of serratus anterior and upper trapezius muscle activity during push up exercises. Am J Sports Med. 2004;32(2):484-93.

9. Bagg SD, Forrest WJ. Electromyographic study of the scapular rotators during arm abduction in the scapular plane. Am J Phy Med. 1986;65(3): 111-24.

10. Kibler WB. The role of the scapula in athletic shoulder function. AM J Sports Med. 1998;26(2):325-37.

11. Sahrmann SA. Diagnosis and treatment of movement impairment syndromes Mosby. 2002;216-22.

12. Dvir $z$, Berme NJ. The shoulder complex in elevation of the arm: a mechanism approach. Biomech. 1978;11(5):219-25.

13. Hardwick DH, Beebe JA, McDonnell MK et al. A comparison of serratus anterior muscle activation during wall slide exercise and other traditional exercises. J Orthop Sport Phys Ther. 2006;36(12);903-10.

14. Prentice WE, Voight ML. Techniques in musculoskeletal rehabilitation. 
McGraw-Hill. 2005;23.

15. Iwasaki T, Shiba N, Matsuse $\mathrm{H}$ et al. Improvement in knee extension strength through training by means of combined electrical stimulation and voluntary muscle contraction. Tohoku J Exp Med. 2006;209(1):3340

16. Lee S, Lee D, Park J. The effects of changes in hand position on the electromyographic activities of the shoulder stabilizer muscles during pushup plus exercises on unstable surfaces. J Phys Ther Sci. 2013;25(1): 1258.

17. Jo SH. Comparative analysis of the right shoulder's muscle activity when lifting lpsilateral and contralateral legs during the push up plus exercise. J Korean Soc Precis Eng. 2015;32(8):749-54.

18. Cram JR, Kasman GS, Holtz J. Introduction to surface electromyography. Maryland Aspen pub. 1998.

19. Kim YH, Tae KS, Song SJ. Evaluation of upper-limb motor recovery after brain injury: the clinical assessment and electromyographic analysis. Phys Ther Korea. 2005;12(1):91-9.

20. Batbayar Y, Uga D, Nakazawa R et al. Effect of various hand position widths on scapular stabilizing muscles during the push-up plus exercise in healthy people. J Phys Ther Sci. 2015;27(8):2573-6. 